\title{
A Mangiferin Monomethyl Ether from Mangifera indica L. ${ }^{1)}$
}

\author{
MasakazU Aritomi ${ }^{2 a}$ and Toshio KaWASAKI ${ }^{2 b)}$ \\ Faculty of Education, Kumamoto University2a) and Faculty of Pharmaceutical \\ Sciences, Kyushu University2b)
}

(Received April 23, 1970)

\begin{abstract}
A new xanthone C-glycoside, named homomangiferin, $\mathrm{C}_{19} \mathrm{H}_{17} \mathrm{O}_{10}\left(\mathrm{OCH}_{2}\right) \cdot 1.5 \mathrm{H}_{2} \mathrm{O}$, decomposing over $250^{\circ}$ without melting, $[\alpha]_{\mathrm{D}}^{14}+8.7^{\circ}$ (pyridine), was isolated from crude mangiferin obtained from the bark of Mangifera indica $\mathrm{L}$. On the basis of chemical and spectral data, it has been formulated as 2-C- $\beta$-D-glucopyranosyl-3-methoxy-1,6,7trihydroxyxanthone (II), i.e., 3-O-methylmangiferin.

Of four possible monomethyl ethers in the aglycone moiety of mangiferin $(\mathrm{I})$, the three, 1-, 3- and 7-methyl ethers, have been synthesized and the identity of homomangiferin with synthetic 3-O-methylmangiferin was confirmed by direct comparison.

The nuclear magnetic resonance spectra of natural and synthetic II and of the heptaacetate (III) measured in pyridine solution showed the signals of methoxyl and acetoxyl groups as a doublet at room temperature $\left(20-23^{\circ}\right)$ and as a sharp singlet at $50^{\circ}$, whereas the methoxyl signals of 1-O- and 7-O-methylmangiferins (VII, XI) and of swertisin (6-C$\beta$-D-glucopyranosyl-7-methoxy-4, ${ }^{\prime}$ - -dihydroxyflavone) (XIV) appeared as a sharp singlet.
\end{abstract}

Mangiferin (I), a coloring matter first isolated in 1908 from Mangifera indica L. (Anacardiaceae), ${ }^{3)}$ was studied extensively by many research groups ${ }^{4)}$ and the conclusive structure has recently been established ${ }^{5-9}$ ) as 2-C- $\beta$-D-glucopyranosyl-1,3,6,7-tetrahydroxyxanthone. It is well known that some of free xanthone derivatives and several flavonoid C-glycosides which seem to be related with xanthone C-glycoside structurally and biogenetically are found in nature accompanied by the corresponding methyl ethers. For example, the aglycone $(1,3,6,7$-tetrahydroxyxanthone $=$ norathyriol) of $\mathrm{I}$ occurs in Athyrium mesosorum MAKINo together with athyriol (3-methyl ether), isoathyriol (6-methyl ether) and I, ${ }^{10)}$ and isovitexin, orientin, isoorientin and epiorientin are respectively coexist with swertisin (7-methyl ether), ${ }^{11)}$ scoparin (3'-methyl ether), ${ }^{12}$ ) swertiajaponin (7-methyl ether) ${ }^{11)}$ and parkinsonin $\mathrm{B}(5,7-$ dimethyl ether). ${ }^{13)}$ However, $\mathrm{I}$ is the only one natural $\mathrm{C}$-glycoside of xanthone derivative

1) Preliminary communication: M. Aritomi and T. Kawasaki, Chem. Pharm. Bull. (Tokyo), 16, 760 (1968).

2) Location: a) Kurokami-machi, Kumamoto; b) Katakasu, Fukuoka.

3) W. Wiechowski, Lotos, 56, 61 (1908) cited from A.L. van Scherpenberg, Rec. Trav. Chim., 35, 346 (1916) [C.A., 11, $41(1917)]$.

4) a) W. Wiechowski, Arch. exp. Pathol. u. Pharmak., 97, 462 Prg. [Chem. Zentr., 94, III, 394 (1923)]; b) K. Gorter, Bull. jard. bot. Buitenzorg, iii, 4, $260(1922)[C . A ., 17,1472(1923)]$; c) S. Iseda, Bull. Chem. Soc. Japan, 30, 625 (1957); d) Idem, ibid., 30, 629 (1957).

5) B.J. Hawthorne, N.F. Janes, F.E. King and J.W.W. Morgan, "Recent Progress in the Chemistry of Natural and Synthetic Colouring Matters and Related Fields," ed. by T.S. Gore, B.S. Joshi, S.V. Sunthankar and B.D. Tilak, Academic Press, New York and London, 1962, p. 331.

6) a) V.K. Bhatia, J.D. Ramanathan and T.R. Seshadri, Tetrahedron, 23, $1363(1967)$; b) V.K. Bhatia and T.R. Seshadri, Tetrahedron Letters, 1968, 1741.

7) L.J. Haynes and D.R. Taylor, J. Chem. Soc. (C), 1966, 1685.

8) a) P.E. Nott and J.C. Roberts, Phytochemistry, 6, 741 (1967); b) Idem, ibid., 6, 1597 (1967).

9) D. Billet, J. Massicot, C. Mercier, D. Anker, A. Matschenko, C. Mentzer, M. Chaigneau, G. Valdener and H. Pacheco, Bull. Soc. Chim. France, 1965, 3006.

10) A. Ueno, Yakugaku Zasshi, 82, 1482 (1962).

11) a) M. Komatsu, T. Tomimori and Y. Makiguchi, Chem. Pharm. Bull. (Tokyo), 15, 1567 (1967); b) Idem, Yakugaku Zasshi, 88, 832 (1968).

12) L. Hörhammer, H. Wagner and P. Bayersdorff, Natuvwiss., 49, 392 (1962).

13) V.K. Bhatia, S.R. Gupta and T.R. Seshadri, Tetrahedron, 22, 1147 (1966). 
ever isolated and, inspite of its rather wide distribution in plants, ${ }^{14,15)}$ none of the corresponding methyl ethers has been reported. ${ }^{16}$ ) This paper deals with the isolation of a new xanthone $\mathrm{C}$-glycoside, named homomangiferin, coexistent with $\mathrm{I}$ and its characterization as 3-O-methylmangiferin.

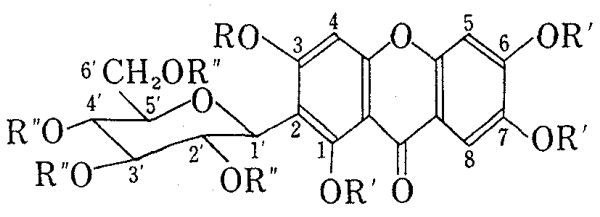

$\mathrm{I}: \mathrm{R}=\mathrm{R}^{\prime}=\mathrm{R}^{\prime \prime}=\mathrm{H}$

II $: \mathrm{R}=\mathrm{Me}, \mathrm{R}^{\prime}=\mathrm{R}^{\prime \prime}=\mathrm{H}$

III $: R=M e, R^{\prime}=R^{\prime \prime}=A c$

$\mathrm{V}: \mathrm{R}=\mathrm{R}^{\prime}=\mathrm{Me}, \mathrm{R}^{\prime \prime}=\mathrm{H}$

$\mathrm{VI}: \mathrm{R}=\mathrm{R}^{\prime}=\mathrm{Me}, \mathrm{R}^{\prime \prime}=\mathrm{Ac}$

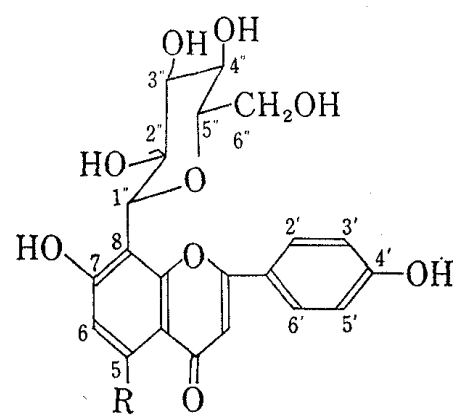

$\mathrm{XII}: \mathrm{R}=\mathrm{OH}$

$\mathrm{XIII}: \mathrm{R}=\mathrm{H}$<smiles>O=c1c2cc(O)c(O)cc2oc2cc(O)cc(O)c12</smiles>

IV

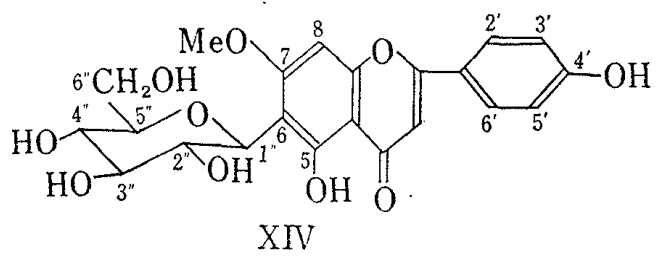

Crude mangiferin ${ }^{17}$ ) from $M$. indica $\mathrm{L}$. which decomposed over $250^{\circ}$ without melting, showed $[\alpha]_{D}^{14}+28.7^{\circ}$ (pyridine) and revealed two spots on paper and on thin-layer of polyamide was separated by column chromatography over polyamide powder into two chromatographically homogeneous materials.

The polar and major (yield, $45 \%$ ) compound was crystallized from aqueous dioxane to give pale yellow needles, $\mathrm{mp} 273^{\circ}$ (decomp.), $[\alpha]_{\mathrm{D}}^{14}+35.5^{\circ}$ (pyridine), which was identified as I by cochromatography on paper and on thin-layer of polyamide with authentic specimen, ${ }^{18)}$ $\mathrm{mp} 273^{\circ}$ (decomp.), and by comparison of their infrared (IR) spectra.

The less polar and minor (yield, 15\%) compound (II) was obtained on crystallization from aqueous dioxane as yellow needles, decomposing over $250^{\circ}$ without melting, $[\alpha]_{D}^{14}+8.7^{\circ}$

14) I. Carpenter, H.D. Locksley and F. Scheinmann, Phytochemistry, 8, 2013 (1969).

15) a) T. Tomimori and M. Komatsu, Yakugaku Zasshi, 89, 410 (1969); b) Idem, ibid., 89, 1276 (1969).

16) Nott and Roberts ${ }^{8 a}$ ) have reported that mangiferin, $\mathrm{mp} 270^{\circ}$ (decomp.), isolated from the bark of $M$. indica L. showed two spots (Rf 0.4 (major) and 0.6 ) on thin-layer of "Polyamidpulver nach Stahl" (Merck) ("Kieselgel H" described in the preliminary communication1) should be read as this) (solvent, EtOH)but the attempts to separate them by fractional recrystallization and column chromatography over polyamide were unsuccessful. After publication of the preliminary communication ${ }^{1}$ on this work, mangiferin 3-methyl ether was isolated together with mangiferin from a plant of Hedusarum genus (P.T. Kondratenko (All-Union Research Institute of Medical Plants), private communication received 17, May, 1969).

17) Obtained by Prof. T. Tsukamoto and Dr. T. Tominaga from the bark of $M$. indica L. grown in Taipei and collected in November. Contamination of a less polar compound had been observed by Kawasaki, et al. (T. Kawasaki and K. Miyahara: Unpublished data) and it gave two spot son paper chromatogram (solvent, $30 \% \mathrm{AcOH}$ ) at $R f 0.61$ (major) and 0.71 and on thin-layer of polyamide (solvent, $\mathrm{MeOH}$ ) at $R f 0.15$ (major) and 0.38 .

18) The sample was kindly furnished by Prof. S. Iseda. It showed two spots at $R f 0.61$ and 0.71 (trace) (on paper; solvent, $30 \% \mathrm{AcOH}$ ) and at 0.15 and 0.38 (trace) (on thin-layer of polyamide; solvent, $\mathrm{MeOH})$. 
TABLE I, UV Spectral Data of Homomangiferin and Its Related Compounds (UV $\left.\lambda_{\max } \mathrm{m} \mu(\log \varepsilon)\right)$

\begin{tabular}{|c|c|c|c|c|}
\hline$\frac{\text { Medium }}{\text { Compound }}$ & $\mathrm{EtOH}$ & $\mathrm{EtOH}-\mathrm{AlCl}_{3}$ & $\begin{array}{l}\text { EtOH- E } \\
\text { AcONa }\end{array}$ & $\begin{array}{c}\mathrm{EtOH}-\mathrm{H}_{3} \mathrm{BO}_{3}- \\
\mathrm{AcONa}\end{array}$ \\
\hline \multirow[t]{3}{*}{ Homomangiferin (II) } & $243(4.47)$ & $238(4.47)$ & \multirow{2}{*}{$\begin{array}{c}244(4.60) \\
258-263(4.37) \\
\text { (shoulder) }\end{array}$} & $237(4.45)$ \\
\hline & $260(4.52)$ & $266(4.47)$ & & 7) $263(4.55)$ \\
\hline & $\begin{array}{l}318(4.18) \\
366(4.13)\end{array}$ & $\begin{array}{l}334(4.07) \\
389(4.13)\end{array}$ & $378(4.41)$ & $\begin{array}{l}323(4.13) \\
373(4.22)\end{array}$ \\
\hline Mangiferin $(\mathrm{I})$ & $\begin{array}{l}242(4.49) \\
259(4.54) \\
318(4.21) \\
368(4.17)\end{array}$ & $\begin{array}{l}235(4.53) \\
266(4.55) \\
332(4.21) \\
400(4.18)\end{array}$ & $\begin{array}{l}241(4.54) \\
264(4.28) \\
384(4.46)\end{array}$ & $\begin{array}{l}241(4.44) \\
263(4.53) \\
326(4.12) \\
377(4.29)\end{array}$ \\
\hline 1,3,6,7-Tetrahydroxyxanthone (IV) & $\begin{array}{l}238(4.32) \\
257(4.50) \\
315(4.16) \\
366(4.08)\end{array}$ & $\begin{array}{l}231(4.40) \\
265(4.41) \\
338(4.11) \\
399(4.07)\end{array}$ & $\begin{array}{l}260(4.52) \\
321(4.08) \\
374(4.21)\end{array}$ & $\begin{array}{l}260(4.55) \\
319(4.10) \\
372(4.20)\end{array}$ \\
\hline 1-Hydroxy-3,6,7-trimethoxyxanthone ${ }^{a)}$ & $\begin{array}{l}256(4.57) \\
309(4.20) \\
359(4.05)\end{array}$ & $\begin{array}{l}232(4.39) \\
264(4.42) \\
332(4.22) \\
404(3.99)\end{array}$ & $\begin{array}{l}257(4.57) \\
309(4.20) \\
360(4.06)\end{array}$ & $\begin{array}{l}257(4.57) \\
309(4.20) \\
359(4.06)\end{array}$ \\
\hline $1,3,6,7$-Tetramethoxyxanthone ${ }^{a)}$ & $\begin{array}{l}253(4.63) \\
301(4.19) \\
348(4.11)\end{array}$ & $\begin{array}{l}253(4.64) \\
301(4.19) \\
348(4.11)\end{array}$ & $\begin{array}{l}253(4.63) \\
301(4.18) \\
348(4.12)\end{array}$ & $\begin{array}{l}253(4.63) \\
301(4.18) \\
348(4.12)\end{array}$ \\
\hline 3-O-Methylmangiferin (synthetic) & $\begin{array}{l}244(4.50) \\
260(4.45) \\
319(4.06) \\
370(4.36)\end{array}$ & $\begin{array}{l}238(4.48) \\
266(4.49) \\
331(3.99) \\
391(4.34)\end{array}$ & $246(4.51)$ & $\begin{array}{l}238(4.50) \\
263(4.51) \\
325(4.05) \\
376(4.20)\end{array}$ \\
\hline 1-O-Methylmangiferin (VII) & $\begin{array}{l}250(4.51) \\
276(4.00) \\
312(4.22) \\
349(3.97)\end{array}$ & $\begin{array}{l}237(4.52) \\
319(4.09) \\
362(4.07\rangle\end{array}$ & $241(4.54)$ & $\begin{array}{l}233(4.48) \\
257(4.45) \\
318(4.19) \\
362(4.21)\end{array}$ \\
\hline \multirow[t]{3}{*}{ 7-O-Methylmangiferin (XI) } & $242(4.42)$ & $233(4.44)$ & $240(4.53)$ & $241(4.51)$ \\
\hline & $258(4.57)$ & $267(4.32)$ & $264(4.25)$ & $\begin{array}{l}260(4.31) \\
\text { (shoulder) }\end{array}$ \\
\hline & $\begin{array}{l}316(4.21) \\
361(4.06)\end{array}$ & $\begin{array}{l}340(4.25) \\
403(4.11)\end{array}$ & $380(4.42)$ & $376(4.33)$ \\
\hline 3,6-Di-O-benzylmangiferin (IX) & $\begin{array}{l}244(4.51) \\
262(4.66) \\
315(4.29) \\
366(4.12)\end{array}$ & $\begin{array}{l}236(4.46) \\
267(4.52) \\
320(4.24) \\
342(4.22) \\
408(4.00)\end{array}$ & $\begin{array}{l}244(4.49) \\
262(4.64) \\
314(4.26) \\
366(4.07)\end{array}$ & $\begin{array}{l}244(4.43) \\
262(4.58) \\
314(4.20) \\
364(4.04)\end{array}$ \\
\hline 7-O-Methyl-3,6-di-O-benzylmangiferin $(\mathrm{X})$ & $\begin{array}{l}244(4.71) \\
262(4.84) \\
316(4.52) \\
361(4.34)\end{array}$ & $\begin{array}{l}235(4.69) \\
271(4.71) \\
341(4.55) \\
404(4.34)\end{array}$ & $\begin{array}{l}244(4.73) \\
262(4.85) \\
316(4.55) \\
361(4.34)\end{array}$ & $\begin{array}{l}244(4.73) \\
262(4.85) \\
316(4.53) \\
361(4.29)\end{array}$ \\
\hline
\end{tabular}

a) Kindly furnished by Prof. S. Iseda

(pyridine). Its color reactions with magnesium and hydrochloric acid, zinc and hydrochloric acid and ferric chloride were similar to those of $\mathrm{I}$ and it analyzed for $\mathrm{C}_{19} \mathrm{H}_{17} \mathrm{O}_{10}\left(\mathrm{OCH}_{3}\right) \cdot 1.5$ $\mathrm{H}_{2} \mathrm{O}$ and yielded an acetate (III), $\mathrm{C}_{34} \mathrm{H}_{34} \mathrm{O}_{18} \cdot 1.5 \mathrm{H}_{2} \mathrm{O}, \mathrm{mp} 173-174^{\circ}$. II resisted hydrolysis with hydrochloric acid, while, on refluxing with hydroiodic acid, ${ }^{4 c)}$ it afforded 1,3,6,7-tetrahydroxyxanthone (IV) and on ferric chloride oxidation ${ }^{19}$ ) arabinose and glucose were provided.

19) B.H. Koeppen and D.G. Roux, Biochem. J., 97, 444 (1965). 


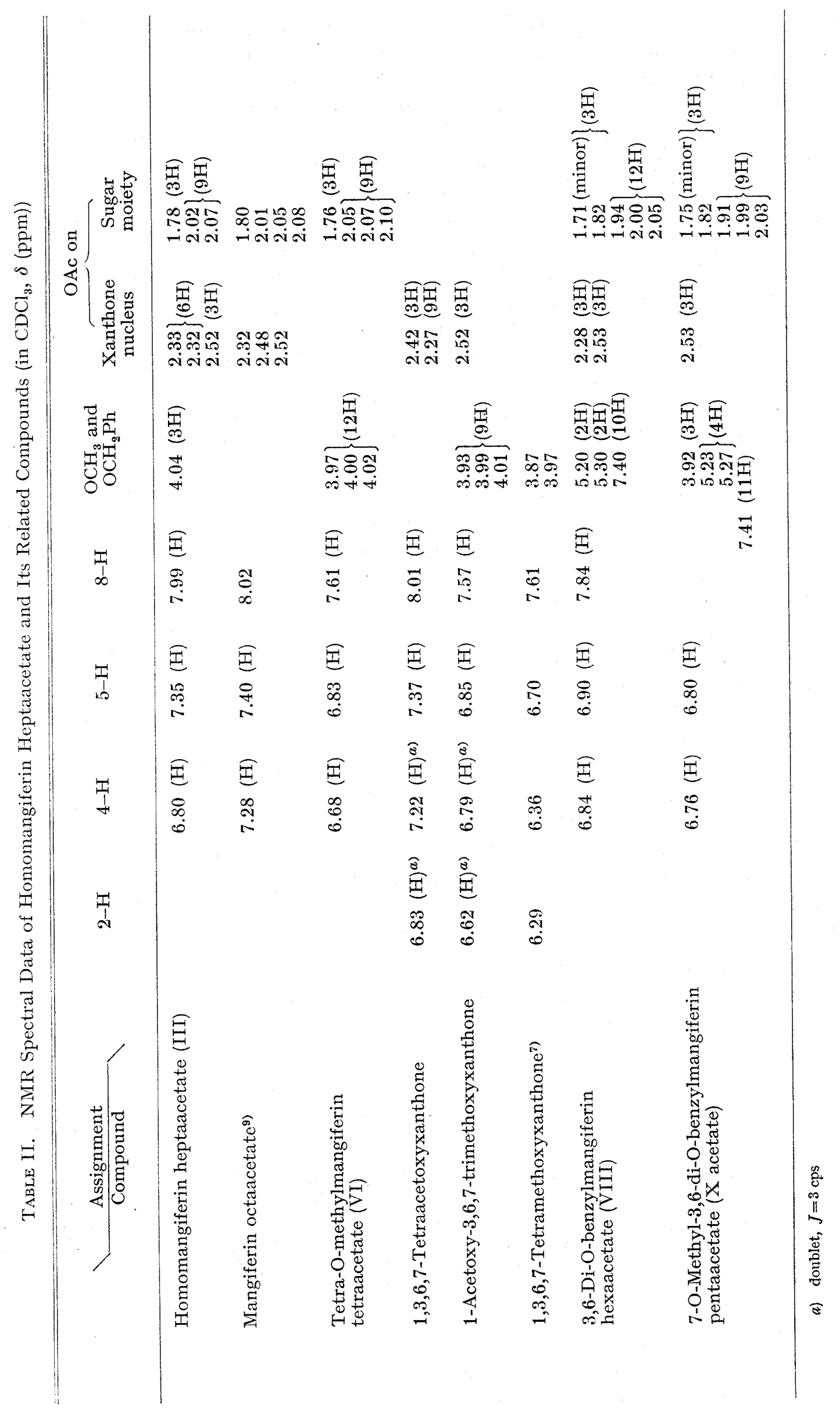


The ultraviolet (UV) spectrum of II (Table I) is hardly distinguishable from that of I and the nuclear magnetic resonance (NMR) spectrum of III $^{20)}$ (Table II) showed a signal (4.04 ppm $(\delta), 3 \mathrm{H}$, singlet) of one methoxyl group on aromatic ring9) and three one proton signals at 6.80 , 7.35 and $7.99 \mathrm{ppm}$ attributable to aromatic protons. ${ }^{7-9)}$ Among the signals due to three aromatic and four aliphatic acetoxyl groups, ${ }^{7-9)}$ the one at $1.78 \mathrm{ppm}$ is assigned to the acetoxyl at C-2' of C- $\beta$-D-glucopyranosyl compounds. ${ }^{21}$ These facts indicate that II is a monomethyl ether of a $\mathrm{C}$ - $\beta$-D-glucopyranoside of 1,3,6,7-tetrahydroxyxanthone.

Methylation of II in a mixture of methanol and dimethylformamide with diazomethane provided $\mathrm{V}$, ${ }^{22)} \mathrm{C}_{23} \mathrm{H}_{26} \mathrm{O}_{11}, \mathrm{mp} 231^{\circ}$, as a sole obtainable pure product, which gave an acetate (VI), $\mathrm{C}_{31} \mathrm{H}_{34} \mathrm{O}_{15} \cdot 1.5 \mathrm{H}_{2} \mathrm{O}, \mathrm{mp} 201^{\circ}$. In the same manner I gave a methyl ether, $\mathrm{mp} 231^{\circ}$ (acetate, $\mathrm{mp} 202^{\circ}$ ), which was identified with V. The UV spectrum of V showed no absorption shift on addition of sodium ethylate and the NMR spectrum (Table II) of VI was in good accordance with the reported one ${ }^{7}$ of $1,3,6,7$-tetra-O-methyl- $2^{\prime}, 3^{\prime}, 4^{\prime}, 6^{\prime}$-tetra-O-acetylmangiferin showing the signals of four acetoxyl groups on sugar moiety at $1.76,2.05,2.07$ and 2.10 $\mathrm{ppm}$ and those of four methoxyl groups-on aromatic ring at $3.97,4.00$ and $4.02 \mathrm{ppm}$. Therefore $\mathrm{V}$ is regarded as 1,3,6,7-tetra-O-methylmangiferin and II is considered to be a monomethyl ether of I.

As given in Table I, the UV spectrum of II showed, in common with those of I and IV, significant absorption shift on addition of boric acid-sodium acetate suggesting the presence of an ortho diphenol grouping ${ }^{23)}$ (hydroxyl groups at C-6 and C-7) in its molecule. The shifts observed in the presence of sodium acetate ${ }^{23 a, 24}$ and on addition of aluminum chloride ${ }^{24)}$ could be ascribed, in comparison with those of reference compounds, to the free hydroxyl groups at C-6 and C-1. The NMR spectrum of III (Table II) shows three signals of aromatic protons and the one at the highest field $(6.80 \mathrm{ppm})$ might be ascribed to the $\mathrm{C}-4$ proton on the basis of the known fact ${ }^{7-9}$ ) that the $\mathrm{C}-2$ and $\mathrm{C}-4$ protons of 1,3,6,7-tetrahydroxyxanthone derivatives appear in the higher field than those at C-5 and C-8. The chemical shift (6.80 ppm) is in good agreement with those (6.68 and $6.79 \mathrm{ppm}$ (Table II)) of the C-4 proton of the reference compounds bearing methoxyl group at $\mathrm{C}-3$ and is significantly higher than those $(7.28,7.22 \mathrm{ppm}$ (Table II)) of the other compounds in which C-3 is occupied by acetoxyl group. The two signals (7.35 and $7.99 \mathrm{ppm}$ ) of III which are respectively assigned ${ }^{7-9)}$ to $5-\mathrm{H}$ and $8-\mathrm{H}$ are in the same region as those $(5-\mathrm{H}, 7.37$ and $7.40 ; 8-\mathrm{H}, 8.02$ and $8.01 \mathrm{ppm})$ of the compounds having acetoxyl groups at C-6 and C-7. Taking into account the general acception ${ }^{9,23 a, 25)}$ that replacement of hydroxyl group or methoxyl group on aromatic ring by acetoxyl group causes a downfield shift of the signals of aromatic protons, especially at ortho position to the substituent, the methoxyl group in III must be located at C-3.

Consequently II is assigned the structure 2 -C- $\beta$-D-glucopyranosyl 3 -methoxy-1,6,7-trihydroxyxanthone, that is 3-O-methylmangiferin.

20) In the NMR spectrum of II measured in pyridine solution at $20^{\circ}$, the signal of methoxyl group was observed as two peaks at 3.77 and $3.68 \mathrm{ppm}$, while in one taken at $50^{\circ}$, it appeared as a singlet at 3.75 $\mathrm{ppm}$. The similar anomaly of the signals of methoxyl and acetoxyl groups was encountered with III. A consideration on this anomaly is described later in this paper.

21) W.E. Hillis and D.G. Roux, Aust. J. Chem., 18, 531 (1965)).

22) The sample, $\mathrm{mp} 184-186^{\circ}$, reported in the preliminary communication ${ }^{1)}$ was later found to be impure showing two spots ( $R f 0.56$ and 0.68$)$ on thin-layer of silica gel $\left(\mathrm{CHCl}_{3}-\mathrm{MeOH}-\mathrm{H}_{2} \mathrm{O}, 7: 3: 1, \mathrm{v} / \mathrm{v}\right.$, lower layer). It was purified by column chromatography over silica gel (EtOAc-EtOH, 9:1, v/v) (cf. M. Aritomi and T. Kawasaki, Chem. Pharm. Bull. (Tokyo), 18, 677 (1970)).

23) a) T.R. Govindachari, B.R. Pai, P.S. Subramanian, U.R. Rao and N. Muthukumaraswamy, Tetrahedron, 23, $243(1967)$; b) K.R. Markham, ibid., 21, 3687 (1965).

24) O.R. Gottlieb, M.T. Magalhaes, M.O. de Silva Pereira, A.A.L. Mesquita, D. de B. Correa and G.G. de Oliveira, Tetrahedron, 24, 1601 (1968)).

25) L.M. Jackmann, "Application of Nuclear Magnetic Resonance Spectroscopy in Organic Chemistry," Pergamon Press, New York, N.Y., 1959. 
In order to confirm the above structure and to obtain some information concerning the anomaly (foot note 20) of the NMR spectra of II and III in pyridine solution, the preparation. of possible four monomethyl ethers of $I$ in the aglycone moiety was then intended.

In the flavonoid chemistry, it is known ${ }^{26)}$ that, in alkaline solution, boric acid protects an ortho diphenol function and the hydroxyl group at C-5 from methylation with dimethyl sulfate or diazomethane. According to Jurd, ${ }^{27)}$ treatment of $3,3^{\prime}, 4^{\prime}, 7$-tetra-O-acetylquercetin with methyl iodide and potassium carbonate in dry acetone provides 5-O-methyl-3,3',4',7-

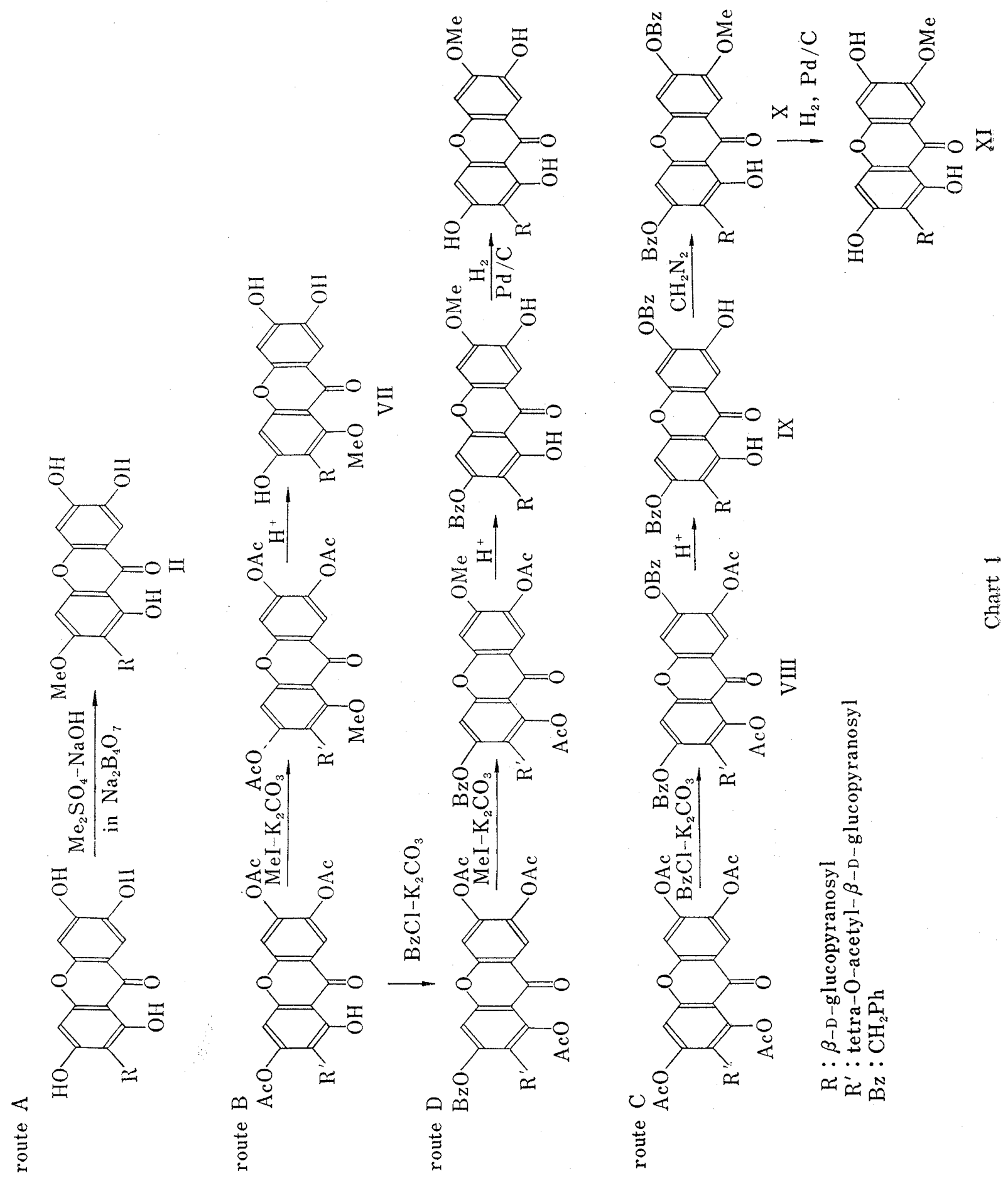

26) a) M. Shimizu and T. Ohta, Yakugaku Zasshi, 71, 879 (1961); b) K.S. Pankajamani and T.R. Seshadri, J. Indian Chem. Soc., 31, 565 (1954) [C.A., 49, 14752 (1955)].

27) a) L. Jurd and L.A. Rolle, J.Am.Chem. Soc., 80, $5527(1958)$; b) L. Jurd, ibid., 80, 5531 (1958). 
tetra-O-acetylquercetin, but the same treatment with benzyl chloride in place of methyl iodide affords 7-O-benzyl-3,3',4',5-tetra-O-acetylquercetin and penta-O-acetylquercetin reacts with methyl iodide or benzyl chloride to give 7-O-methyl- or 7-O-benzyl-3,3',4',5-tetra-Oacetylquercetin. The hydroxyl groups at $\mathrm{C}-1$ (and C-8) and C-3 (and C-6) of xanthone derivatives correspond respectively to those at $\mathrm{C}-5$ and $\mathrm{C}-7$ of flavonoids and the former chelates with boric acid ${ }^{28)}$ and the latter shows the stronger acidity than the hydroxyl groups of the other positions. ${ }^{23 b, 28,29)}$ In view of these facts the syntheses of four monomethyl ethers of I were carried out according to the scheme shown in Chart 1.

Methylation of I in borax solution with dimethyl sulfate and sodium hydroxide after the procedure of Pankajamani, et al. ${ }^{26 b}$ and subsequent purification through chromatography over polyamide yielded mono-O-methylmangiferin (II), $\mathrm{C}_{20} \mathrm{H}_{20} \mathrm{O}_{11} \cdot 1.5 \mathrm{H}_{2} \mathrm{O}$, which decomposed over $250^{\circ}$ without melting and gave an acetate, $\mathrm{mp} 170-173^{\circ}$. Its structure, 3-methyl ether, was confirmed by UV absorption shift ${ }^{23,24)}$ (Table I) caused by addition of diagnostic reagents.

Treatment of $2^{\prime}, 3,3^{\prime}, 4^{\prime}, 6,6^{\prime}, 7$-hepta-O-acetylmangiferin ${ }^{5)}$ with methyl iodide and potassium carbonate in dry acetone afforded an amorphous product. Because its purification was unsuccessful, the crude product was hydrolyzed with hydrochloric acid and the resulting material, revealing three spots at $R f 0.61$ (I), 0.64 (VII) and 0.74 (trace) on paper chromatogram, was fractionated by chromatography over polyamide powder. Recrystallization from aqueous dioxane of the fraction consisting of major product $(R f 0.64)$ gave VII as pale yellow needles, $\mathrm{C}_{20} \mathrm{H}_{20} \mathrm{O}_{11}, \mathrm{mp} 285-286^{\circ}$ (decomp.), with the foregoing charing at about $281^{\circ}$. It gave green color while I, II and XI (described later) turned to greenish or reddish brown with ferric chloride ${ }^{30}$ and its UV spectrum ${ }^{31}$ ) had the longest wave length absorption maximum at lower than those of I, II and XI (Table I). ${ }^{30 b, 32)}$ These facts correspond to those in 5-hydroxylated and 5-methoxylated flavones. The NMR spectrum of VII in pyridine at $23^{\circ}$ shows a singlet due to methoxyl group at $4.32 \mathrm{ppm}$ which is significantly lower ${ }^{25)}$ than those of II $\left(3.68,3.77 \mathrm{ppm}\right.$ (doublet) at $20^{\circ} ; 3.75 \mathrm{ppm}$ at $\left.50^{\circ}\right)$ and XI $\left(3.82 \mathrm{ppm}\right.$ at $\left.22^{\circ}\right)$. Accordingly VII is considered as 1-methyl ether.

Refluxing of octa-O-acetylmangiferin $\left.{ }^{6} a\right)$ with benzyl chloride and potassium carbonate in dry acetone provided colorless needles (VIII), $\mathrm{C}_{45} \mathrm{H}_{42} \mathrm{O}_{17}, \mathrm{mp} 195-196^{\circ}$. Its NMR spectrum (Table II) indicated the presence of two benzyloxy groups $(5.30(2 \mathrm{H})$ and $5.20(2 \mathrm{H})$, $2 \times \mathrm{PhCH}_{2} ; 7.40(10 \mathrm{H}) \mathrm{ppm}$, aromatic proton) and two acetoxyl groups $(2.53(3 \mathrm{H}), 1-\mathrm{OAc}$ and $2.28(3 \mathrm{H}) \mathrm{ppm})^{9,23 a, 25)}$ and three protons $(7.84,6.90$ and $6.84 \mathrm{ppm})$ on xanthone nucleus. Comparison of the chemical shifts of the three aromatic protons with those of other mangiferin derivatives indicated the presence of the two benzyloxy groups at $\mathrm{C}-3$ and $\mathrm{C}-6 . .^{\mathbf{9}, 23 a, 25)}$ Acid hydrolysis of VIII afforded 3,6-di-O-benzylmangiferin (IX) as pale yellow needles, $\mathrm{C}_{33} \mathrm{H}_{30} \mathrm{O}_{11}$.

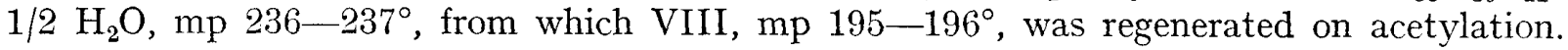

28) J.C. Roberts, Chem. Rev., 61, 591 (1961).

29) a) K.R. Markham, Tetrahedron, 20, 991 (1964); b) Idem, ibid., 21, 1449 (1965).

30) a) H. Nakamura and G. Fukuchi, Yakugaku Zasshi, 60, $449(1940)$; b) N. Morita, Chem. Pharm. Bull. (Tokyo), 8, 59 (1960).

31) The UV absorption shift caused by addition of sodium acetate and boric acid-sodium acetate are in harmony with the expected structure, 1-O-methylmangiferin, of VII, while that observed in the presence of aluminum chloride is incompatible (Table I) and it could be accounted for by the presence of ortho diphenol function (T. Swain, Chem. Ind., 1954, 1480; J.B. Harborne, ibid., 1954, 1142). The UV absorption of 7-O-methylmangiferin (XI) described later is shifted, inspite of the absence of ortho diphenol function, by addition of boric acid-sodium acetate and showed the close resemblance with that in sodium acetate. Thus, in accordance with the recent observations (H.H. Lee and C.H. Tan, J. Chem. Soc., 1965, 2743; B. Jackson, H.D. Locksley and F. Scheinmann, ibid. (C), 1967, 871), UV absorption shifts may be employed for the structure assignment of xanthone derivatives only when the reference compounds are examined in parallel.

32) L. Jurd, "The Chemistry of Flavonoid Compounds," ed. by T.A. Geissman, Pergamon Press, Oxford, London, New York, Paris, 1962, p. 107. 
A bathochromic shift of the longest wave length absorption maximum in the UV spectrum of IX (Table I) on addition of aluminum chloride and no shift with sodium acetate and boric acid-sodium acetate supported the structure. Methylation of IX with diazomethane gave a monomethyl ether $(\mathrm{X}), \mathrm{C}_{34} \mathrm{H}_{32} \mathrm{O}_{11} \cdot \mathrm{H}_{2} \mathrm{O}, \mathrm{mp} 212-213^{\circ}$, which is regarded as mangiferin 3,6-di-O-benzyl-7-methyl ether and the structure was supported by the ferric chloride test ${ }^{30}$ ) (brown), UV absorption shift with diagnostic reagents ${ }^{23,24)}$ (Table I) and by the fact that the NMR spectrum of its acetate, mp $173-174^{\circ}$, shows only one signal of the acetoxyl group on xanthone nucleus, the chemical shift $(2.53 \mathrm{ppm})$ of which is identical with that of the $\mathrm{C}-1$ acetoxyl group of other mangiferin derivatives (Table II). Catalytic debenzylation of $\mathrm{X}$ pro vided 7-O-methylmangiferin (XI), $\mathrm{C}_{20} \mathrm{H}_{20} \mathrm{O}_{11}, \mathrm{mp} 237^{\circ}$.

The attempted preparation of 6-O-methylmangiferin according to the Chart 1 (route $\mathrm{D}$ ) was unsuccessful, because the reaction of $2^{\prime}, 3,3^{\prime}, 4^{\prime}, 6,6^{\prime}, 7$-hepta-O-acetylmangiferin with benzyl chloride failed to give any homogeneous compound.

Comparison of three synthetic monomethyl ethers of I with natural II verified the identity of II with 3-methyl ether.

As refered to in foot note 20, the NMR spectra of II and III taken in pyridine solution showed the signals of methoxyl and acetoxyl groups as doublet. The same anomaly was observed in the spectra of synthetic II ( 3.72 and $3.65 \mathrm{ppm}$, taken at $23^{\circ}$ in pyridine solution), VIII (1.71 (minor) and $1.82 \mathrm{ppm}$, taken at $23^{\circ}$ in deuteriochloroform) and $\mathrm{X}$ acetate $(1.75$ (minor) and $1.82 \mathrm{ppm}$, taken at $22^{\circ}$ in deuteriochloroform). Eade, et al. ${ }^{33)}$ reported that the NMR spectra of the acetates of vitexin (XII) and bayin (XIII) measured in deuteriochloroform showed a splitting or broadening of the signals of aromatic and acetoxyl protons and that the anomaly might be ascribed to the presence of isomers due to the restricted rotation about the bond between sugar and aromatic moiety. In analogy to this presumption and taking into account the fact that the spectra of II and III are temperature dependent, existence of two rotational isomers respectively in both compounds may be assumed. However, not only the spectrum of XI but also those of VII and, in particular, of swertisin (XIV) (and its acetate) which holds the same partial structure as II showed the signal of methoxyl group (and acetoxyl group) as a sharp singlet (XI, $3.82 \mathrm{ppm}$, singlet, at $22^{\circ}$; VII, $4.32 \mathrm{ppm}$, singlet, at $23^{\circ}$; XIV, $3.77 \mathrm{ppm}$, singlet at $22^{\circ}$; XIV acetate, $3.94 \mathrm{ppm}$, singlet $\left(\mathrm{OCH}_{3}\right), 2.28,2.09$, $2.07,1.95,1.89 \mathrm{ppm}, 5 \times$ singlets $(\mathrm{OAc})$, at $\left.22^{\circ}\right)$, and the anomaly is still open to discussion.

\section{Experimental $\left.{ }^{34}\right)$}

Isolation of Homomangiferin (II) from Crude Mangiferin_Crude mangiferin ${ }^{17}$ (2 g) was refluxed with $\mathrm{MeOH}$ and the extract was chromatographed over a column of polyamide $(150 \mathrm{~g})$ using the same solvent. The eluate was checked by thin-layer (TLC) (method a) and paper chromatographies (PPC) and separated into two chromatographically homogeneous fractions, Fr. $1(0.3 \mathrm{~g}), \operatorname{Rf} 0.38$ (TLC (method a)) and 0.71 (PPC); Fr. $2(0.9 \mathrm{~g})$, Rf 0.15 (TLC (method a)) and 0.61 (PPC).

33) R.A. Eade, W.E. Hillis, D.H.S. Horn and J.J.H. Simes, Aust. J. Chem., 18, 715 (1965).

34) Melting points were measured in capirrary and are uncorrected. Optical rotations were determined with a JASCO automatic polarimeter Model DIP-SL and UV spectra were recorded on a Hitachi automatic spectrometer Model EPS-2 and a Shimazu SV 50-A. IR spectra were taken in $\mathrm{KBr}$ discs using a JASCO Model DS-301 and NMR spectra were measured on a JEOL Model JNM-3H-60 and a JNM$\mathrm{C}-60-\mathrm{H}$ at $60 \mathrm{MHz}$ in $\mathrm{CDCl}_{3}$ with $\mathrm{Me}_{4} \mathrm{Si}$ as an internal standard. The chemical shifts are given in $\delta$ values (ppm). Polyamide powder (Nylon 66) $(\overline{\mathrm{M}}=8000$. Distribution of particle size: $>95 \mu, 13 \%$; $95-40 \mu, 15 \% ; 40-30 \mu, 18 \% ; 30-20 \mu, 31 \% ; 20-15 \mu, 14 \% ;<15 \mu, 9 \%$ ) was kindly donated by Ube Industries Ltd. TLC were run over polyamide using $\mathrm{MeOH}$ as a solvent (method a) or Kiesel gel $\mathrm{G}$ nach Stahl in the solvent system $\mathrm{CHCl}_{3}-\mathrm{MeOH}-\mathrm{H}_{2} \mathrm{O}(7: 3: 1, \mathrm{v} / \mathrm{v}$, lower layer) (method $b)$, and the spots were visualized under UV light or by heating with dil. $\mathrm{H}_{2} \mathrm{SO}_{4}$. Phenolic compounds were examined by PPC (Toyo Roshi No. 50, ascending, solvent: $30 \% \mathrm{AcOH}$, visualized under UV light and by spraying with $\left.5 \% \mathrm{Na}_{2} \mathrm{CO}_{3}\right)$. For column chromatography, Kanto silica gel (100-200 mesh) was used. 
Fr. 2 was crystallized from dioxane- $\mathrm{H}_{2} \mathrm{O}(1: 1, \mathrm{v} / \mathrm{v})$ to give yellow needles, $\mathrm{mp} 273^{\circ}$ (decomp.) with foregoing blackening at about $250^{\circ},[\alpha]_{\mathrm{b}}^{14}+35.5^{\circ}(c=1.08$, pyridine). It gave orange color with $\mathrm{Mg}-\mathrm{HCl}$ or $\mathrm{Zn}-\mathrm{HCl}$, greenish brown color with $\mathrm{FeCl}_{3}$, and brown fluorescence on PPC and yellow fluorescence on TLC of polyamide. On spraying with $\mathrm{Na}_{2} \mathrm{CO}_{3}$ it showed brown spot with yellow fluorescence on PPC. Mixed melting point determination and cochromatography with an authentic sample ${ }^{18}$ ) and comparison of IR spectra indicated its identity with mangiferin. Anal. Calcd. for $\mathrm{C}_{19} \mathrm{H}_{18} \mathrm{O}_{11}: \mathrm{C}, 54.03 ; \mathrm{H}, 4.30$. Found: C, 53.93; H, 4.56 .

Fr. 1 was crystallized from dioxane- $\mathrm{H}_{2} \mathrm{O}(1: 1, \mathrm{v} / \mathrm{v})$ giving yellow needles (IT), which began to blacken at about $250^{\circ}$ and gradually decomposed without melting. $[\alpha]_{D}^{14}+8.7^{\circ}(c=0.58$, pyridine $)$. Anal. Calcd. for $\mathrm{C}_{19} \mathrm{H}_{17} \mathrm{O}_{10}\left(\mathrm{OCH}_{3}\right) \cdot 1.5 \mathrm{H}_{2} \mathrm{O}: \mathrm{C}, 51.84 ; \mathrm{H}, 5.00 ; \mathrm{OCH}_{3}, 6.70 ; \mathrm{H}_{2} \mathrm{O}, 5.8$. Found: $\mathrm{C}, 51.65 ; \mathrm{H}, 5.37 ; \mathrm{OCH}_{3}$, $6.74 ; \mathrm{H}_{2} \mathrm{O}, 6.2$. It is sparingly soluble in organic solvents except dioxane, pyridine and dimethylformamide and soluble in $\mathrm{NaOH}$ and $\mathrm{Na}_{2} \mathrm{CO}_{3}$ solutions with yellow coloration. It showed the same color and fluorescence as I with $\mathrm{Mg}-\mathrm{HCl}, \mathrm{Zn}-\mathrm{HCl}$ and $\mathrm{FeCl}_{3}$, and on $\mathrm{PPC}$ and $\mathrm{TLC}$ of polyamide. NMR (pyridine) $\delta$ (ppm): 3.68, 3.77 at $20^{\circ} ; 3.75$ at $50^{\circ}\left(\mathrm{OCH}_{3}\right)$.

Homomangiferin Heptaacetate (III) - - A solution of II $(0.2 \mathrm{~g})$ in pyridine $(10 \mathrm{ml})$ and $\mathrm{Ac}_{2} \mathrm{O}(10 \mathrm{ml})$ was left stand overnight, and heated on a water bath for 30 min. The reaction mixture was poured into $\mathrm{H}_{2} \mathrm{O}$, the precipitates were collected, washed with $\mathrm{H}_{2} \mathrm{O}$, dried and crystallized from $\mathrm{MeOH}$ to give III as colorless needles, mp 173-174. Anal. Calcd. for $\mathrm{C}_{34} \mathrm{H}_{34} \mathrm{O}_{18} \cdot 1.5 \mathrm{H}_{2} \mathrm{O}: \mathrm{C}, 53.90 ; \mathrm{H}, 4.91 ; \mathrm{H}_{2} \mathrm{O}, 3.6$. Found: $\mathrm{C}, 53.71$; $\mathrm{H}, 5.08 ; \mathrm{H}_{2} \mathrm{O}, 3.2$. It gave no color with $\mathrm{FeCl}_{3}$. UV $\lambda_{\max }^{\mathrm{Etorg}} \mathrm{m} \mu(\log \varepsilon): 246(4.69), 300(4.23)$. NMR $\left(\mathrm{CDCl}_{3}\right)$ : shown in Table II. NMR (pyridine at $\left.22^{\circ}\right) \delta(\mathrm{ppm}): 4.00,3.93\left(3 \mathrm{H}, \mathrm{OCH}_{3}\right), 2.69,2.60(3 \mathrm{H}, \mathrm{OAc}), 2.35$ $(3 \mathrm{H}, \mathrm{OAc}), 2.30,2.19,2.10,2.06,2.00,1.95$ (minor peak) $\left(15 \mathrm{H}, 5 \times \mathrm{OAc}\right.$ ); (at $\left.50^{\circ}\right) 3.95\left(3 \mathrm{H}, \mathrm{OCH}_{3}\right), 2.61$ $(3 \mathrm{H}, \mathrm{OAc}), 2.30(3 \mathrm{H}, \mathrm{OAc}), 2.25,2.14,2.08,2.02,1.96(15 \mathrm{H}, 5 \times \mathrm{OAc})$.

Treatment of II with $\mathrm{HCl}$ - A suspension of II $(10 \mathrm{mg})$ in conc. $\mathrm{HCl}(1 \mathrm{ml})$ was heated on a water bath for $10 \mathrm{~min}$. The reaction mixture was diluted with $\mathrm{H}_{2} \mathrm{O}$, and the precipitates were collected by centrifugation and washed with $\mathrm{H}_{2} \mathrm{O}$. They showed no spot on PPC except that of II. The supernatant was neutralized by passing through the column of Amberlite IR $45\left(\mathrm{OH}^{-}\right.$type) and concentrated in vacuo. It was negative to Molisch reaction and showed no spot of reducing sugar.

Treatment of II with HI-A solution of II $(0.1 \mathrm{~g})$ in phenol $(0.5 \mathrm{~g})$ was refluxed with HI $(d, 1.7,2 \mathrm{ml})$ for $5 \mathrm{hr}$. The reaction mixture was poured into $10 \% \mathrm{NaHSO}_{3}$ solution, and the precipitates were collected, washed with $\mathrm{H}_{2} \mathrm{O}$, dried and then acetylated with $\mathrm{Ac}_{2} \mathrm{O}$ and pyridine at room temperature overnight. The product was precipitated by adding $\mathrm{H}_{2} \mathrm{O}$, collected on filter and crystallized from EtOH to colorless needles, mp $191-192^{\circ}$, undepressed on admixture with authentic 1,3,6,7-tetraacetoxyxanthone, mp $191-192^{\circ}$.

Ferric Chloride Oxidation of II-II $(0.1 \mathrm{~g})$ was refluxed with aqueous solution of $\mathrm{FeCl}_{3}(0.5 \mathrm{~g}$ in $15 \mathrm{ml}$ $\mathrm{H}_{2} \mathrm{O}$ ) for $6 \mathrm{hr}$. After being cooled the reaction mixture was filtered and the filtrate was passed through the columns of Amberlite IR $120\left(\mathrm{H}^{+}\right.$type) and IR $45\left(\mathrm{OH}^{-}\right.$type) and evaporated in vacuo to a syrup, which was examined by PPC $\left(\mathrm{BuOH}\right.$-pyridine $-\mathrm{H}_{2} \mathrm{O}(3: 2: 1, \mathrm{v} / \mathrm{v})$, double ascending method). The chromatogram showed two spots of reducing sugars and the running distance $(13.3 \mathrm{~cm}$ ) and color (reddish brown with $p$-anisidine $\cdot \mathrm{HCl}$ ) of the major spot were same as those of arabinose run in parallel and the other spot (running distance, $11.9 \mathrm{~cm}$, yellowish brown) was identified with that of glucose.

Duplication of the procedure with I gave the same result.

Tri-0-methylhomomangiferin (V) and Tri-0-methylhomomangiferin Tetraacetate (VI) ——To a solution of II $(500 \mathrm{mg})$ in dimethylformamide $(25 \mathrm{ml})$ and $\mathrm{MeOH}(100 \mathrm{ml})$ was added an etheral solution of $\mathrm{CH}_{2} \mathrm{~N}_{2}$ prepared from $10 \mathrm{~g}$ of nitrosomethylurea, and the mixture was left stand at room temperature overnight. After removal of the solvent (finally in vacuo), the residue which on TLC (method b) revealed six spots with blue fluorescence at $R f 0.56$ (main), $0.68,0.74$ (trace), $0.83,0.87$ and 0.91 was chromatographed on silica gel $(50 \mathrm{~g})$ using EtOAc-EtOH $(9: 1, \mathrm{v} / \mathrm{v})$ as solvent to give two fractions: Fr. $1(160 \mathrm{mg}), \operatorname{Rf}(\mathrm{method} \mathrm{b}) 0.68$, $0.74,0.83,0.87,0.91$; Fr. $2(320 \mathrm{mg}), R f(\operatorname{metod} \mathrm{b}) 0.56$. Recrystallization of Fr. 2 from MeOH yielded $\mathrm{V}$ as colorless needles, $\mathrm{mp} 231^{\circ}$, negative to $\mathrm{FeCl}_{3}$ test. Anal. Calcd. for $\mathrm{C}_{23} \mathrm{H}_{26} \mathrm{O}_{11}: \mathrm{C}, 57.74 ; \mathrm{H}, 5.48$. Found: $\mathrm{C}, 57.67 ; \mathrm{H}, 5.65$.

$\mathrm{V}$ was treated with $\mathrm{Ac}_{2} \mathrm{O}$ and pyridine and the product was crystallized from $\mathrm{MeOH}$ to give an acetate (VI) as colorless needles, mp 201 ${ }^{\circ}$. Anal. Calcd. for $\mathrm{C}_{31} \mathrm{H}_{34} \mathrm{O}_{15} \cdot 1 / 2 \mathrm{H}_{2} \mathrm{O}: \mathrm{C}, 56.79 ; \mathrm{H}, 5.38$. Found: C, 56.88; H, 5.52 .

Tetra-0-methylmangiferin (V) and Tetra-0-methylmangiferin Tetraacetate (VI)-I (500 mg) was methylated in the same manner as above. The reaction mixture showing six spots on TLC (method b) at $R f 0.56$ (main), $0.68,0.74$ (trace), $0.83,0.87$ and 0.91 was separated by column chromatography over silica gel (EtOAc-EtOH $9: 1, \mathrm{v} / \mathrm{v})$ ) into two fractions: Fr. $1(150 \mathrm{mg}), R f(\operatorname{method}$ b) $0.68,0.74,0.83,0.87$, 0.91 ; Fr. $2(360 \mathrm{mg}), R f(\operatorname{method} \mathrm{b}) 0.56$. Further separation of Fr. 1 was unsuccessful.

Fr. 2 was crystallized from $\mathrm{MeOH}$ to give $\mathrm{V}$ as colorless needles, $\mathrm{mp} 231^{\circ}$. Anal. Calcd. for $\mathrm{C}_{23} \mathrm{H}_{26} \mathrm{O}_{11}$ : $\mathrm{C}, 57.74 ; \mathrm{H}, 5.44$. Found: C, 57.68; H, 5.58. UV $\lambda_{\max }^{\text {tor }} \mathrm{m} \mu(\log \varepsilon): 253(4.54), 310(4.22), 343$ (3.96), unshifted by adding EtONa. It gave no color with $\mathrm{FeCl}_{3}$. Admixture with the sample of $\mathrm{V}$ prepared from II did not depress the melting point and their IR spectra and $R f$ values on TLC (method $\mathrm{b}$ ) were identical.

$\mathrm{V}$ was acetylated with $\mathrm{Ac}_{2} \mathrm{O}$ and pyridine at room temperature overnight to give an acetate (VI) as colorless needles (from $\mathrm{MeOH}$ ), mp 202 . Anal. Calcd. for $\mathrm{C}_{31} \mathrm{H}_{34} \mathrm{O}_{15}: \mathrm{C}, 57.58 ; \mathrm{H}, 5.26$. Found: $\mathrm{C}$, 57.67; 
H, 5.51. NMR $\left(\mathrm{CDCl}_{3}\right)$ : Table II. No melting point depression was observed on admixture with the corresponding derivative from II.

Synthesis of II by Partial Methylation of I-To a solution of I (500 mg) in $5 \% \mathrm{Na}_{2} \mathrm{~B}_{4} \mathrm{O}_{7}(60 \mathrm{ml})$ was added $\mathrm{Me}_{2} \mathrm{SO}_{4}(3.6 \mathrm{ml})$ and $5 \% \mathrm{NaOH}$ solution $(50 \mathrm{ml})$ under stirring during $3 \mathrm{hr}$. After stirring for another $1 \mathrm{hr}$, the reaction mixture was acidified to $\mathrm{pH} 4.0$ with $10 \% \mathrm{HCl}$ and the gelatinous precipitates were removed by centrifugation. The supernatant was passed through a column of Amberlite IR $120\left(\mathrm{H}^{+}\right.$type) and the eluate was chromatographed on polyamide powder $(50 \mathrm{~g})$. The column was repeatedly washed with $\mathrm{H}_{2} \mathrm{O}$ and then percolated with $\mathrm{MeOH}$. Removal of $\mathrm{MeOH}$ afforded yellow crystalline solid consisting of three substances of $R f$ (PPC) 0.61 (I), 0.71 (II) and 0.83 (trace), which was rechromatographed over polyamide $(50 \mathrm{~g})$ using $\mathrm{MeOH}$. The fractions giving one spot at $R f 0.71$ were combined and evaporated to dryness. An yellow crystalline residue was treated with a small amount of hot $\mathrm{MeOH}$ and the hardly soluble solid was crystallized from dioxane- $\mathrm{H}_{2} \mathrm{O}(1: 1, \mathrm{v} / \mathrm{v})$ to give yellow needles $(110 \mathrm{mg})$, decomposing over $250^{\circ}$ without melting, $[\alpha]_{\mathrm{D}}^{23}+5.1^{\circ}(c=0.78$, pyridine $)$. Anal. Calcd. for $\mathrm{C}_{20} \mathrm{H}_{20} \mathrm{O}_{11} \cdot 1.5 \mathrm{H}_{2} \mathrm{O}: \mathrm{C}, 51.84 ; \mathrm{H}, 5.00$. Found: $\mathrm{C}, 51.84 ; \mathrm{H}, 5.29$. NMR (pyridine at $\left.23^{\circ}\right) \delta(\mathrm{ppm}): 3.65,3.72\left(\mathrm{OCH}_{3}\right)$. UV spectral data are given in Table I. Its IR spectrum and $R f$ value were identical with those of natural II. Acetylation gave an acetate as colorless needles (from $\mathrm{MeOH}$ ), mp 170-173 , undepressed on admixture with III.

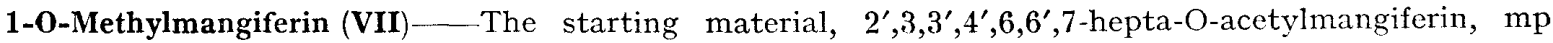
$228-229^{\circ},[\alpha]_{\mathrm{D}}^{24}-12.9^{\circ}\left(\mathrm{c}=1.28, \mathrm{CHCl}_{3}\right)$, was prepared by Hawthorne method. ${ }^{5)}$

A mixture of hepta-O-acetylmangiferin $(1.0 \mathrm{~g})$, methyl iodide $(1.0 \mathrm{~g})$ and $\mathrm{K}_{2} \mathrm{CO}_{3}(4.0 \mathrm{~g})$ in dry acetone $(40 \mathrm{ml})$ was refluxed for $2 \mathrm{hr}$ and the reaction mixture was filtered and evaporated to dryness giving an yellow residue. Since the attempted purification of the product by chromatography and by recrystallization failed, the crude material $(960 \mathrm{mg})$ was hydrolyzed on refluxing with $\mathrm{MeOH}(30 \mathrm{ml})$ and $10 \% \mathrm{HCl}$ $(30 \mathrm{ml})$ for $2 \mathrm{hr}$. On removal of $\mathrm{MeOH}$ yellow needles were separated out, which were collected by filtration, washed with $\mathrm{H}_{2} \mathrm{O}$ and dried. They $(550 \mathrm{mg}$ ) showed three spots, $R f 0.61$ (I), 0.64 (VII), 0.74 (trace), on PPC and were chromatographed over polyamide $(100 \mathrm{~g})$ using EtOH as solvent to give two fractions: Fr. 1 $(230 \mathrm{mg}), R f(\mathrm{PPC}) 0.64$ (blue fluorescence); Fr. $2(280 \mathrm{mg}), R f(\mathrm{PPC}) 0.61$ (brown fluorescence).

Fr. 1 was crystallized from dioxane- $\mathrm{H}_{2} \mathrm{O}(1: 1, \mathrm{v} / \mathrm{v})$ to give VII as pale yellow needles, $\mathrm{mp} 285-286^{\circ}$ (decomp.) with the foregoing blackening at about $281^{\circ} .[\alpha]_{\mathrm{D}}^{23}+87.4^{\circ}(c=0.52$, pyridine). Anal. Calcd. for $\mathrm{C}_{20} \mathrm{H}_{20} \mathrm{O}_{11}: \mathrm{C}, 55.05 ; \mathrm{H}, 4.62$. Found: $\mathrm{C}, 55.33 ; \mathrm{H}, 4.69$. It gave green color with $\mathrm{FeCl}_{3}$. NMR (pyridine at $\left.23^{\circ}\right) \delta(\mathrm{ppm}): 4.32\left(\mathrm{OCH}_{3}\right)$. UV spectra with diagnostic reagent are summarized in Table I.

3,6-Di-O-benzyl-1,2',3', 4',6 6 7-hexa-0-acetylmangiferin (VIII)__Octa-O-acetylmangiferin (0.8 g) prepared from $\mathrm{I}$ after the procedure of Iseda $\left.{ }^{35}\right)$ was refluxed with benzyl chloride $(0.8 \mathrm{ml}), \mathrm{K}_{2} \mathrm{CO}_{3}(3.2 \mathrm{~g})$ and III $(0.1 \mathrm{~g})$ in dry acetone $(20 \mathrm{ml})$ for $7 \mathrm{hr}$. After filtration, the reaction mixture was treated with a large amount of hexane to give white precipitates, which were crystallized from MeOH to provide VIII as colorless needles $(580 \mathrm{mg})$, mp 195-196 ${ }^{\circ}$. Anal. Calcd. for $\mathrm{C}_{45} \mathrm{H}_{42} \mathrm{O}_{17}: \mathrm{C}, 63.23 ; \mathrm{H}, 4.92$. Found: $\mathrm{C}, 63.49 ; \mathrm{H}, 4.98$. NMIR data are listed in Table II.

3,6-Di-0-benzylmangiferin (IX)___ VIII (1.20 g) was hydrolyzed on refluxing with MeOH (240 ml) and $10 \% \mathrm{HCl}(120 \mathrm{ml})$ for $6 \mathrm{hr}$. The hydrolysate was diluted with $\mathrm{H}_{2} \mathrm{O}$ (about $500 \mathrm{ml}$ ), and the precipitates were collected, washed with $\mathrm{H}_{2} \mathrm{O}$ and crystallized from dil. $\mathrm{MeOH}$ to give IX as pale yellow needles (860 mg), mp 236-237 . Anal. Calcd. for $\mathrm{C}_{33} \mathrm{H}_{30} \mathrm{O}_{11} \cdot 1 / 2 \mathrm{H}_{2} \mathrm{O}: \mathrm{C}, 64.81 ; \mathrm{H}, 5.07$. Found: $\mathrm{C}, 64.53 ; \mathrm{H}, 5.13$. UV absorption shifts caused by adding diagnostic reagents are shown in Table $\mathrm{I}$.

IX afforded an acetate as colorless needles, mp 195-196 ${ }^{\circ}$, undepressed on admixture with VIII.

7-0-Methyl-3,6-di-0-benzylmangiferin (X)_-To a solution of IX $(300 \mathrm{mg})$ in acetone (30 $\mathrm{ml})$ was added an etheral solution of $\mathrm{CH}_{2} \mathrm{~N}_{2}$ prepared from $3 \mathrm{~g}$ of nitrosomethylurea. After leaving stand for $3 \mathrm{hr}$, the reaction mixture which revealed on TLC (method b) two spots at $R f 0.48$ (brown fluorescence) and 0.34 (blue fluorescence) was evaporated and the residue was chromatographed over silica gel (20 g) using $\mathrm{CHCl}_{3}-\mathrm{EtOH}(9: 1, \mathrm{v} / \mathrm{v})$ as solvent. The fractions revealing only one spot at Rf 0.48 were combined, evaporated to dryness and the residue was crystallized from MeOH to give $\mathrm{X}$ as pale yellow needles $(\mathbf{1 0 0} \mathrm{mg})$, mp 212-213 ${ }^{\circ}$. Anal. Calcd. for $\mathrm{C}_{31} \mathrm{H}_{32} \mathrm{O}_{11} \cdot \mathrm{H}_{2} \mathrm{O}: \mathrm{C}, 64.35 ; \mathrm{H}, 5.40$. Found: $\mathrm{C}, 64.06 ; \mathrm{H}, 5.27$. It gave brown color with $\mathrm{FeCl}_{3}$ and $\mathrm{UV}$ absorption shifts were observed only on addition of $\mathrm{AlCl}_{3}$ (Table I).

Acetylation of $\mathrm{X}$ and recrystallization of the product from $\mathrm{MeOH}$ provided an acetate as colorless needles, $\mathrm{mp} 173-174^{\circ}$. NMR data are given in Table II.

7-0-Methylmangiferin $(\mathbf{X I})$ - $\mathrm{X}(100 \mathrm{mg})$ in $\mathrm{AcOH}(10 \mathrm{ml})$ was shaken with $\mathrm{Pd} / \mathrm{C}(10 \%)(100 \mathrm{mg})$ under the hydrogen stream. The catalysts were filtered off and washed with hot pyridine. The filtrate and the washings were combined, evaporated to dryness and the residue was crystallized from dioxane$\mathrm{H}_{2} \mathrm{O}(1: 1, \mathrm{v} / \mathrm{v})$ to give XI as pale yellow needles $(60 \mathrm{mg}), \mathrm{mp} 237^{\circ},[\alpha]_{\mathrm{D}}^{19}+27.2^{\circ}(c=0.79$, pyridine $)$. Anal. Calcd. for $\mathrm{C}_{20} \mathrm{H}_{20} \mathrm{O}_{11}: \mathrm{C}, 55.05 ; \mathrm{H}, 4.62$. Found: $\mathrm{C}, 55.09 ; \mathrm{H}, 4.87$. It gave reddish brown color with $\mathrm{FeCl}_{3}$

35) S. Iseda, The Journal of Kumamoto Women's University, 9, 45 (1957). 
and showed on PPC one spot with brown fluorescence at $R f 0.66$. NMR (pyridine at $\left.22^{\circ}\right) \delta(\mathrm{ppm}): 3.82$ $\left(\mathrm{OCH}_{3}\right)$. UV data are given in Table $\mathrm{I}$.

Acknowledgement The authors are grateful to Prof. T. Tsukamoto of Fukuoka University for kind gift of crude mangiferin and to Prof. S. Iseda of Kumamoto Women's University for the authentic samples of mangiferin, 1-hydroxy-3,6,7-trimethoxyxanthone and 1,3,6,7-tetramethoxyxanthone. Thanks are also due to Dr. K. Miyahara, Faculty of Pharmaceutical Sciences, Kyushu University, for NMR and IR spectra and helpful discussions, to Mr. M. Ishii, Faculty of Engeneering, Kumanoto University, for the UV data and to the members of the Central Analysis Room of Kyushu University for microanalyses. 